\title{
Power and Personality
}

\author{
Valentina Pervushina, Valentina Gladkikh \\ State University of Justice, Central Branch, Voronezh, Russia
}

\begin{abstract}
The term power is widespread in social and political theory. The polysemantic nature of the term power has led to a variety of definitions of this concept. The classical articulation of the definition of power/authority was given by the classics of sociology-Weber and Parsons. But classic articulation of power is defined in terms of relation-activity matrix of power, namely, authority. The paper conceptualizes power as the unity of power-kratia and power-arhiya and analyzes it from the point of view of functioning and development of society and personality. Such conception of power focuses on the ways in which personalities are constituted not only by power relations but are capable to change socio-cultural and economic conditions of their existence. So, power and freedom, resistance and transformation of power relations are complementary to one another.
\end{abstract}

Keywords: power/authority, power-kratia, the power-arhiya, conformism/non-conformism, personality

The problem of power is central in social and political theory. The scholars connect various interpretations of the concept power with the polysemantic of the word, motivating this fact by negligence in dealing with this term and words close to it in meaning-power, influence, force, domination, and coercion. This creates many problems for both political practice and social theory. In the philosophical literature, the manifestation of power is being studied at various levels: economic, political, social, and spiritual. The question of the classification of power is raised. This classification is given on different grounds. Vyatr's typology of power includes behavioral, teleological, instrumentalist, and structuralist definition of power. He defined power in terms of imposing one's will on another and conflict theory (Vyatr, 1979, pp. 158-159). Ledyaev (2000) offered a frame of reference for analyzing power by the source and motives of subordination of the object of power to the subject of power-force, coercion, persuasion, manipulation, and authority (pp. 6-19) ${ }^{1}$. Various approaches to the definition of power and critical analysis are given in Stanford Encyclopedia of Philosophy (Allen, 2016, pp. $1-29)$.

\section{Matrix of Power/Authority: Pre-history}

The polysemantic meaning of term power makes a generally accepted definition of power impossible. But, based on the connotations of term power, it is possible to determine the matrix of power. Within it power is an asymmetric relation between subject and object; the object is always subordinate side acting under imposing of the subject. It turned out that the relational-activity matrix of power had become the subject of theoretical

\footnotetext{
Valentina Pervushina, full professor, Department of Social Sciences and Humanities, State University of Justice, Central Branch, Voronezh, Russia.

Valentina Gladkikh, full professor, Department of Social Sciences and Humanities, State University of Justice, Central Branch, Voronezh, Russia.

1 See: Ilyin, M. V., Melville, A. Yu., 1997. Power//Polis. No. 6, p. 148; Khalipov, V., 2002. Kratology—The Science About Power. Conception. Moscow: Economy, pp. 18-20.
} 
analysis in the second half of the 19th century. The pioneers in the study of power were Marx, Engels, Lenin, and Weber (Weber, 1991, pp. 511-545, 628-644) ${ }^{2}$. In the Marxian sense power is being understood from the point of view of the social class approach. The state and, accordingly, the state power appear under the class stratification of society and are the result of the struggles between classes. Marx focused his search on state power in terms of suppression (of one class to another), domination, subjection, and coercion.

Weber was first credited with having introduced a distinction between Macht (Power) and Herrschaft (Authority). The Weberian sociology of power is based on his understanding of social action and its typology. Power (Macht) manifests by itself in the ability of one's will to impose on others. The subordinate side is forced to do something that it would not have done that, if it were possible. Authority (Herrschaft) is legitimate, and generates voluntary consensus of the ruled, recognized by them. Weber proposed his typology of "pure types" of legitimate domination, coinciding with the analysis of typical "motives of social action-behavior". He viewed the traditional, charismatic, and rational-legal legitimating of power. The belief in the legitimacy and sacredness of the existing power and social order is a foundation for traditional legitimate domination. This type of domination is adequate to the traditional type of social action and corresponds to Gemeinschaft community. Another type of legitimate domination is a charismatic one. Unlike the traditional type, it is based not on force of habit, but extraordinary, emotionally colored attitude of devotion and faith in a charismatic leader. The charismatic type of legitimate domination actualized the dynamism of traditional society (affective behavior was adequate to this type of domination), based, as the previous type of traditional legitimacy, on the personal relationship between the power and subordinate sides. Rational-legal type of legitimate domination is based on purpose-rational action and the formal legal principle. All are subject not to the individual, but to the established laws (this type of legitimacy functions in Gesellschaft, society). This is the principle, according to Weber, that contributed to the development of modern capitalism within the framework of formal rationality and the formation of bureaucracy as a "technically pure" type of legal domination.

Finally, the classical founders of Western sociology, Marx and Weber, proposed a relational-activity model of power (power is always a subject-object relation of domination, subordination, and coercion, which has the character of voluntariness or coercion and is implemented in social action), functioning at the level of social institutions and acquiring the character of formalized domination through law and the state in industrial society. Mainly such a narrow understanding of power as a legally legitimate type of domination (authority) prevails in sociological and political literature. The concept of power in the Parsonsian sense was explained traditionally as a system phenomenon in essence. Parsons examined power in the context of authority, as a relational-activity model, adding to this model an attributive feature: power-authority should act as a generalized mediator between the various subsystems of society. Power has an impact on different processes in the social system, so it can be placed in any kind of relationship: economic, political, and moral. Power is an essential attribute of a social system whose overall goal is to achieve stability and order. The economic system (economic rationality) performs the function of adaptation, the political-the achievement of social goals, the legal system (forced rationality) - the function of integration, cultural - the maintenance of the identification of the system through value-normative standards. It seemed that Parsons defined power-authority in broader conception of power. But as a prototype for the political system, Parsons took the economic subsystem and

\footnotetext{
2 See: Lenin, V. I., 1962. Complete Works. Vol. 33. Moscow: Politizdat, pp. 5-22; Marx, K., Engels, F., 1955. Complete Works. Vol. 21, Moscow: Politizdat, pp. 23-178.
} 
viewed it as a structural identity for the political one. The political system is oriented, as well as the economic one, to a generalized form of exchange similar to money in the economic subsystem. There is an extrapolation of the theory of exchange for the political sphere; hence there is an analytic oversimplication. Parsons' comparison of power to money is a universal means of exchange, an ideal construction that causes certain difficulties in the study of real power in a particular historical process. The Parsonsian attributive-relational-activity model of power exists within the framework of the functional paradigm (Parsons, 2000, pp. 685-689) ${ }^{3}$.

Later, this model of power is reproduced in the works of other scholars. Luhmann ${ }^{4}$ analyzes power as a symbolic means of communication allowing actor-carrier of it to have certain advantages over others in choosing the most profitable way of social action. Power is regulated by the code of legal-non-legal relations. Secondary coding of power is manifested in its functional equivalents. They include the state, which is the "highest point of generalization of power", the core reference of all operations of the political system.

The same model of power is being analyzed in political theory. Power is considered in the terms of social interaction (subject-object relations), in which one side has the ability to impose one's will on another (Ball, 1993, pp. 36-38).

The analysis of power as a fundamental category in the social and political theory thus highlights the attributive-relational-activity model power, proposed by the classical founders of sociology, Weber and Parsons.

\section{Defining Power}

We define power as an integral socio-cultural phenomenon (unity of power-kratia and power-arhiya, functioning in the social system) ${ }^{5}$. The sense of power-kratia is to maintain social order, normative standards and control. Power-kratia is exercised through the function that promotes the continuous reproduction of social institutions. It acts as a mediator, relieving the tension between social control and conditions that prevent from conflicts and contribute to the integrity of the social system. Power-kratia is the intersection of many discourses: economic, social, legal, psychological, and cultural. But society is not only a social system; it is also constituted as an association of uniting individuals and social groups. Power-arhiya softens the force dominant of power-kratia, actualizes its emancipation, and articulates its self-reflection, and the desire for dialogue. The authenticity of the second nature of power is realized in cooperation and in the allocation of resources; in the coordination of various political functions. Power should not only divide human beings, but also unite them and have the ability to convince others of the appropriateness of joint actions that exclude violence and domination

\footnotetext{
${ }^{3}$ Parsons, T., 1969. Politics and Social Structure. On the Concept of Political Power. New York: Free Press; Parsons, T., 1956. Economy and Society (co-authorized with N. J. Smelser.). New York: Free Press.

${ }^{4}$ Parsons' influence on Luhmann undeniable. Luhmann uses the same principle of extrapolation of the economic subsystem as a methodological reference point. He sees the advantage of this approach in the possibility of comparing power with other types of communication tools: truth or money. He regards the same orientation towards the model of functional differentiation of society, allowing forcing the potential of conflicts and consensus. Power is exercised through communicative relations activities. See: Luhmann, N., 2001. Power. Moscow: Praxis.

5 The dual justification of power stems from the internal dyadic conception of power (power-kratia and power-arhiya). The paper by F. Fede on power analyzes two "verbal constructions of power" used in the Ancient culture. The power to heal, to do, to have the capacity for anything; it is synonymous with opportunity, virtue; the source and meaning of the beginning of power. This is the power-arhiya. It is possible to identify power as domination, seizure over someone, when they talk about God and people; obedience, dictatorship of Empire, authority, force of control, hardness, when it comes to metals. This is the power-kratia. In the Middle Ages the civil principle was carried out through the power-kratia, and the spiritual one (power-arhiya) - through the Church.
} 
as a means of solving problems. This explanation of power in communicative perspective was suggested by Arendt (1970) and Habermas (1977). From the liberal tradition, modern communicative theories of power differ in a broader understanding of contractualism, which includes, along with legal regulation, aesthetic and moral criteria. The communicative model of power takes into account the process of deliberation of power, the expansion of freedom and human emancipation. The constitutive concept of power-arhiya is revealed in terms of development theory and theory of personality.

The functional dimension of power-kratia requires an analysis of society as a system that involves not only interaction of its components but the functioning of the social whole through its cells (networks), reproducing themselves through this social whole, acting as the intersection of various factors ${ }^{6}$. The functioning of the system is marked by minor quantitative changes that do not lead to its transformation. From the position of functional approach, power-kratia is aimed at maintaining stability and social order. The normative regulation defines the boundaries, forms, conditions of behavior of individuals and groups in the most important areas of society. Moreover, the norms function not only in terms of will, influence, or coercion, but also have information and value aspects. The normative aspect of culture is inherent in both material and spiritual spheres of human activity. Through the implementation of normative standards, the identity of the social system is maintained. The normative aspect of culture is the source of ruling, control, and functioning of power and involves manipulation. Manipulation is a form of existence of the power itself, a form of social regulation, control and order of ruling. Manipulation is the technology of power associated with normalization, classification, ranking, group and individual identification, the formation of forms of subjectivity within the socio-cultural system. Values and norms of culture are given a priori. Power maintains social order through cultural legitimacy, the institutionalization of a system of values, and the maintenance of the normative order. In this context, power-kratia can be defined as a function that contributes to the maintenance of the socio-cultural identity of the system. In this sense, power-kratia is total by its nature.

Through the institutionalization of value system, cultural legitimization of normativity and power order is carried out. The functional dimension of power and power relations is based on the unity of power and knowledge. The forms of social space are changing, and social control by itself is acquiring more subtle forms from psychological pressure through the media, cyberspace to economic coercion. Power-kratia is monologue, and manipulates the consciousness of individuals, placing them in the status-role ranking, rejecting those who do not correspond to it. This is dangerous with permanent resistance of the objects of control. Power constitutes the identity of objects through labels, but this does not imply the puppet nature of the objects of power. Human beings do not respond to social life in a predetermined way. They construct themselves through the interpretations of events, other people, and one self (Blumer, 1969).

Understood in this context, power-kratia differs from the traditional relational-activity model of power developed by Marx, Weber, and Parsons, who revealed the meaning of the concept of power coercion through the assertion of the primacy of exchange in the economic and political sphere. Marx, for example, explained, that the market forced, although this coercion appeared on the surface in an erased form: in the form of entry into the exchange of legal reciprocity, in the form of contractual relations of "equality" and "freedom". Compulsion within the framework of power-kratia exists before any exchange. It is not necessary to use Marx's basic-superstructure structure of society. Coercion is initially present outside the legal domination, creating an

\footnotetext{
${ }^{6}$ In this sense, the functional need of power was defended by G. Spencer, K. Marx, T. Parsons, N. Luhmann.
} 
additional dimension for it, without which the existence of a legal institution of power would be impossible. This is the area of functioning of micro physics of power, which is found not in the institutions of power, of a particular social group, elite, etc., but in the technique, form of functioning of power. Power-kratia becomes invisible (the subject of ruling is invisible), gets into every pore of the social body, not using methods of inquiry by torture, and acts gently, through control, rules, exams, tests, giving the necessary functions of a body, gestures, etc., preparing them for obedience (this situation was brilliantly researched by Foucault).

\section{Power-Kratia and Personality}

Micro physics of power-kraitia is universal, supporting the functioning of the entire system of coercion in society. There is no longer any need for arrest or sentencing, as individuals are in a universal process of normalization, and the impact of power on an unconscious level is part of their life strategies. Therefore, the action of power is manifested implicitly. Thus, the negative form of power (violence) and the positive form of power-kratia (regulation and maintenance of the integrity of society) are closely linked. It is possible to avoid the tragic picture of the image of power-kratia even in its positive form, as it has been regarded by Foucault, if we do not consider social control in its original entity as a unity of self-categorization and self-identification of individuals within the status-role space ${ }^{7}$. This is reflected in the role conception of personality, in which a personality is considered to be a carrier of certain social status and roles that meet the normative requirements of the social system and social order. Power functions not only at the level of social institutions, but also in everyday life, ranking people into groups, categories, distributing them "according to individual qualities, binds them to their own identity, imposing some law of truth that they need to find in themselves" (Foucault, 2007, p. 593).

The role conception of personality (Cooley, Mead, Parsons, and others) ${ }^{8}$ focused on the socio-typical manifestations of personality in recurring situations. The role conception of personality actualizes the relationship between personality and society. Therefore, the concepts of "social role", "social status", "role expectations", "role conflict", and "value-normative standards" are the main semantic units in the construction of the relationship between the individual and society. Parsons, combining behavioral (theory of social action) and systemic approaches, identified the main analytical units of the connection of personality and society-culture, social system, personality, behavioral organism, with the main role assigned to culture. Values and normative standards are the primary culture. The assimilation and transmission of cultural patterns through social institutions - family and education - is necessary for the adaptation, achievement of goal, integration, and maintenance of the social system. Institutionalization is impossible without the integration of standardized expectations with different forms of social control and sanctions, inducing a person to social action. It is power-authority with its domination.

The role conception of personality is unthinkable outside the framework of the functional paradigm, the main purpose of which is to describe the structural and functional conditions for maintaining the status quo of the social system. It is possible in case of satisfaction of social needs of individuals, adequate motivated behavior of individuals in social system and transmission of cultural symbols. From the functional perspective,

\footnotetext{
7 A link of power-knowledge was offered by M. Foucault. See: Foucault, M., 1996. Archeology of Knowledge. Kiev: Nika-Center; Foucault, M., 1998. The History of Sexuality. Volume 1. The Will to Knowledge. London: Penguin; Foucault, M., 1998. Discipline and Punish. The Birth of the Prison. Moscow: AD Marginem.

8 See: Parsons, T., 1998. System of Modern Societies. Moscow: Aspect Press; Parsons, T., 2000. The Structure of Social Action. Moscow: Academic Project.
} 
every subsystem has a unit of its own. There are needs-attitudes for a personality; status-roles - for the social system; value orientation-for the culture. The maintenance of the social system is achieved through the internalization of social regulations, manifesting in conformist behavior; there is an identification of a human being and a function. The negative aspects of the role conception of personality are clearly manifested. The self-determination of the personality is narrowing down; individuality disappears ${ }^{9}$. There is only one label- "successful"/“unsuccessful". The social order of the market economy type - the formation of homo economics - is being clearly traced: A successful and prosperous person is in demand, in opposition to the loser or downshifter. The role conception of personality is linked with the labeling theory. The triumph of order and the power of the majority equally lead to a deadlock (Fede \& Vezen, 2010, p. 151).

\section{Power-Arhiya, Social Change, and Personality}

It is necessary to supplement functional analysis with other methods: development theory and the phenomenological-existential approach for broader understanding of power. From the point of view of social development, power-arhiya exists in the dialogue space, if in a given society there is a possibility of reverse effect of objects of management on ruling elite through democratic institutions and civil society. Power, ranking the objects of its paternalistic influence, brings to the social discourse conditions for the destruction of itself, generating discontent and conflicts. Analysis of power is impossible without understanding the phenomenon of freedom, which has an ontological status. If the power does not hear, resistance to it is carried out at the level of social groups in radical forms (protest of yellow vests in France) through social movements and revolutions (Skocpol, 1979, pp. 3-47). It should be noted that the changes taking place in a particular socio-cultural system have an impact on all mankind. Thus, Locke's the legal formula (life, property, and freedom) served as the basis on which the concept of "universal rights" has appeared concretized in the doctrine of "human and civil rights". In the age of Enlightenment natural rights acquired the status of universal and fundamental rights. Such changes in mind of mankind required the recognition not of an atomic being as a substantial unit of society, but of humanity on the whole. Later, in the 19th and 20th centuries, the popularity of Marxism contributed to the awareness of social human rights. In the middle of the 20th century, protection against racism and gender discrimination had become a fundamental right. Finally, the combination of constitutional, legal, and social rights has led to the formation of a society of "social welfare", which provided high living standards of well-being, and there was a "guaranteed freedom".

Changes in the spiritual sphere (values), which determine the way of life through stereotypes, standards of behavior, are due to non-conformist personalities. Their activities go beyond the social system; they speak from the position of non-system, non-conformism. It is necessary to use phenomenological-existential approach for understanding of this phenomenon. Existential consciousness, united with the heroic freedom, defended the right to independence from the historical and social situations, was directed against amor fati. There is no fate that would not overcome contempt ${ }^{10}$. The fate of human being became the work of his/her hands. A person can be a history partner; no event passes them by. This is the most radical conclusion drawn from Husserl's

\footnotetext{
${ }^{9}$ In modern social science the subject is understood not as an atomic individual, but the activity of the subject through the practice of selfhood, is recognized "an intersubjective concept of personality emphasizing the social, cultural, historical, and linguistic structure of personal identity" is actualized (The Philosophy of Law. An Encyclopedia, 1999//Ed. by Christopher Berry Grag. London, New York, Vol. 1, p. 132).

10 Camus, A., 1990. A Rebellious Man. Philosophy. Policy. Art. Moscow: Politizdat; Sartre, J.-P., 1994. Nausea. Moscow: Republic.
} 
doctrine of the intentional construction of the world by the subject. Any references to the circumstances, situations, etc., are inappropriate. Freedom of choice is inextricably linked to the responsibility and self-determination of the personality. "Being for-itself" is the subject of decision and choice. It is not necessary to demand from existential consciousness of the solution of pragmatic problems in the field of the functional relations of the exchange; it is not focused on, although it is impossible to deny the practical orientation of the existential consciousness. The heroic freedom, which is the ideal of existential consciousness, commands to perform duty without "any hope of success". In critical, crisis situations, extremely difficult and dramatic (war, prison, incurable disease), it turned out to be more practical than pragmatic consciousness, which had a sobering effect on people who unjustifiably hope for the near resolution of their tormenting problems, helped to counteract the attitudes of social pragmatism and political shortsightedness, served as an antidote to the mood of pessimism and despair arising after the defeat of overly optimistic forecasts, promises, and helped to preserve the meaning and significance of the actions, which in fact, could not immediately lead to desirable results (Drobnizky, 1974, p. 361).

The existentialist consciousness with its focus on absolute justice revised norms and traditions, made criticism of practical reason, settled "in chaos", and rethought the boundaries of what was allowed and what was not allowed, as if expanding the "boundaries of sin", defended itself against the power of state and society. Hence, it is the interest of existentialists (Camus, especially Sartre) to pathology and ugliness.

The existentialist consciousness presupposes the self-improvement, giving meaning to the world and importance of relationships with others.

Reaching the transcendent level, the existential consciousness gives a different understanding of the individual-spiritual experience: The uniqueness of the single subjectivity is emphasized. Uniqueness is built into the absolute. The analysis of freedom from the point of view of existential consciousness makes its research in the framework of socio-cultural determination, utilitarian and pragmatic rationality irrelevant. Another anthropological setting - a unique subjectivity acts as a "generator of meaning"-ontologizes internal freedom as a factor of being. The inner freedom is regarded as a gift. A human being constructs the world according to his/her own laws in accordance with the sense significance of human subjectivity. Freedom is the internal basis of the existential consciousness.

Phenomenological-existential approach allows going beyond the status-role conception of the personality, to oppose the personality and society. A human being is in a constant process of forming a choice of decisions in the fight against the alienated social world. The choice of value preferences comes from a human being by himself/herself. Husserl's understanding of the intentionality of consciousness is supplemented in existentialism by the acceptance of the thesis of "openness outside", the uniqueness of "being-in-the-world", the recognition of going beyond empirical existence, and the breakthrough to the transcendent. The sphere of duty is recognized as a way of human existence, designed to change the existing value-normative standards, to supplement the "ontological insufficiency", to compensate it through the initial movement "out of oneself". A human being has the right not depend on historical and social situations. And this is a riot against the deterministic picture of the world, the normative rationality of power-kratia. Freedom acts as a necessity by itself. A human being is condemned to be free. In the free choice, personality chooses his/her subject world, and comprehends the code of being, regardless of the established value-normative standards. Power-kratia with its manipulative practice does not work. The space of non-conformist freedom is connected not only with social liberation, but also with the experience of forming one's own self in everyday life, with the issue of individual 
self-determination and self-realization. The individual self goes beyond the action of power relations and it is not power that shapes its subjectivity, but it itself. Such non-conformist practices have been known since antiquity - cynics, heretics in the Middle Ages, idiots in Russia, representatives of the ethics of non-violence (Thoreau, Tolstoy, etc.). As a result, there is a process of detraditionalization, change of value-normative standards. Giddens (2004, pp. 30, 31, 43) revealed the profound changes that have occurred with the institution of marriage and close relationships (relationships of love, friendship, and kinship), transforming from a social institution into a means of emotional self-realization of the individual. This is also a kind of evidence of social emancipation, both at the level of social institutions and in everyday life. There has been a shift from phallocentric culture associated with reproductive attitudes and male sexual experience to plastic sexuality, including female sexual experience and the "flowering of homosexuality". Plastic sexuality, according to Giddens, becomes a personal characteristic associated with the "I (Me)—conception" of a human being, his/her self and identity. It is considered as a component of personal life style.

Changes in society lead to the emergence of new conditions for the formation of individual choice. Self-consciousness is already based on the self-determination of the individual. The very act of choice is associated with a critical attitude to the world, requiring individual and personal self-control. It is affirmed the dignity of the personality, not requiring "reinforcement". Such a person has greater independence from the pressure of external circumstances, customs, traditions, and public pressure. Such a person has a well-developed individual motivation, based on the normative-evaluative regulation, individually-selective attitude to the values, self-reflection. The object of power becomes an autonomous subject, ready to consider instructions creatively, to adapt to changing social conditions (Foucault, 1998, pp. 144-145).

Non-conformism is based in its spiritual basis on the original meaning of freedom as "Ungrund", chaos, abyss. In existentialism, freedom-chaos is transformed into absolute freedom of will and absolute freedom of choice, that is a riot. Meaningfully, the freedom of existential consciousness can be defined within the framework of relationship: the human being - absolute. Even Kant (1965) admitted that the recognition of the spontaneity of freedom meant the denial of God as the "essence of all essences" independent of anything and determines everything (p. 478). Freedom is ontological. It is manifested in the freedom of consciousness, transformed into freedom of choice and self-determination of the individual. Such a freedom revises the existing stereotypes, criticizes practical reason, and rethinks the boundaries of what is permissible and what is not permissible, contributing to the revision of the values determining the development of all mankind, its spiritual renewal.

\section{Conclusions}

The matrix of power includes the relation of subject and object. In the narrow sense of the word power, authority is a subject-object relationship, functioning in terms of suppression, domination, and coercion. The subject is designated. It is a state. Power is legitimate. In a broad sense, power (unity of power-kratia and power-arhiya) is an intersection of many discourses - from socio-economic to spiritual, including manipulation. The subject of power is uncertain, and blurred. Power-kratia is analyzed from the perspective of both functional approach and development theory. Power-kratia focuses on maintaining the stability and socio-cultural identity of the system, and ranks individuals in accordance with the status-role structure determined by the value-normative standards. Society determines the social action-behavior of the individual. Power-kratia functions in a monologue space. Power, considered from the point of view of development theory, implies 
resistance of the object of violence, coercion, and manipulation in various forms - from public condemnation to radical practices (social movements and revolutions). The understanding of power from the point of view of development theory is impossible without freedom, realized both at the level of groups and at the personal level. At the group level, it is a socio-political practice that leads to changes in the socio-political structure. In terms of non-conformism, there is a reverse impact of the individual on society; a transformation of value-normative standards is pointed out; and we are already dealing with another socio-cultural system, included in the conditions of globalization in the universal interaction with others. Power-arhiya reflects the prospects of revising the term power as domination, oppression and is articulated on definition of power as cooperation and partnership. Thus, the definition of the concept of "power" reveals its essence through the use of different approaches - functional, development theory, and phenomenological-existential.

\section{References}

Allen, A. (2016). Feminist perspectives on power. Stanford Encyclopedia of Philosophy. Retrieved from https://plato.stanford. edu/entries/feminist-power/

Arendt, H. (1970). On violence. New York: Harcourt Brace Jovanovich.

Ball, T. (1993). Power. Policy. 5, 36-43.

Blumer, H. (1969). Symbolic interactionism: Perspective and method. New Jersey: Prentice-Hall, Inc.

Drobnizky, O. G. (1974). On concept of moral. Moscow: Publishing House "Science".

Fede, F., \& Vezen, F. (2010). Philosophy French and Philosophy German / F. luck. Imaginary. Power / F. Fede. Per. with CHF. / Filosofiya frantsuzskaya i filosofiya nemetskaya / F. Vezen. Voobrazhaemoe. Vlast / F. Fede. Per. s fr. Russia: Editorial URSS.

Foucault, M. (1998). The history of sexuality. Volume 1. The will to knowledge. London: Penguin.

Foucault, M. (2007). Hermeneutics of the subject. St. Petersburg: Science.

Giddens, A. (2004). Transformation of intimacy. Sexuality, love, and eroticism in modern societies. St. Petersburg: Peter.

Habermas, J. (1977). Hannah Arendt's communications concept of power. Social Research, 44(1), 3-24.

Habermas, J. (1987). Philosophical discourse of modernity: Twelve lectures. Cambridge, MA: The MIT Press.

Habermas, J. (2001). Involvement of another: Essays on political theory. St. Petersburg: Science.

Kant, I. (1965). Collected works in 6 volumes, Vol. 3. Moscow: Thought.

Ledyaev, V. G. (2000). Forms of power: Typological analysis. Policy, 2, 6-19.

Parsons, T. (2000). The structure of social action. Moscow: Academic Project.

Skocpol, T. (1979). States and social revolutions: A Comparative Analysis of France, Russia and China. Cambridge: Cambridge University Press.

Vyatr, E. (1979). Sociology of political relations. Moscow: Progress.

Weber, M. (1991). Selected works. Moscow: Progress. 